\title{
PENGGUNAAN METODE QUALITY FUNCTION DEPLOYMENT (QFD) DALAM REDESAIN KOMPOR BATIK ELEKTRIK "KOMBATRIK"
}

\author{
Siti Lestariningsih ${ }^{1}$, Jono $^{2}$ \\ ${ }^{1,2)}$ Fakultas Teknik, Prodi Teknik Industri, Universitas Widya Mataram \\ Dalem Mangkubumen KT.III/237 Yogyakarta \\ Email: siti_lestariningsih@yahoo.com, Yonuwm@yahoo.co.id
}

\begin{abstract}
ABSTRAK
Penelitian dengan judul “ Penggunaan Metode Quality Function Deployement (QFD) dalam Redesain Kompor Batik Elektrik "KOMBATRIK" untuk mengetahui karakteristik-karakteristik kebutuhan pengguna kompor batik elektrik yang perlu diperhatikan dalam membuat kompor batik elektrik baru yang berdasarkan House of Quality $(H O Q)$.

Dalam penelitian ini telah dilakukan analisis dan evaluasi kebutuhan pengrajin (voice of customer) terhadap kompor batik elektrik "KOMBATRIK" yang ada saat ini. Hasil penelitian bahwa Karakteristik Kombatrik yang diperlukan pengrajin meliputi bentuk kompor dan posisi tombol (On Of), sehingga desain Kombatrik baru dengan bentuk wajan ditambah pengait canting dan tinggi tombol (On Of) berada ditengah $(6,8 \mathrm{Cm})$.

Harapannya setelah dilakukan penelitian dapat dibuat kombatrik baru agar keinginan pengguna dapat terpenuhi.
\end{abstract}

Kata Kunci: Rumah Kualitas, Karakteristik kompor batik elektrik, QFD

\section{ABSTRACT}

The research entitled "Use of the Quality Function Deployement (QFD) Method in Redesigning the" KOMBATRIK "Electric Batik Stove to find out the characteristics of users of electric batik stoves that need to be considered in making new electric batik stoves based on House of Quality (HOQ).

In this study an analysis and evaluation of the needs of craftsmen (voice of customers) has been carried out on the current "KOMBATRIK" electric batik stove. The results of the study showed that the characteristics of Kombatrik needed by the craftsmen included the shape of the stove and the position of the button (On Of), so the design of the new Kombatrik with the shape of the pan plus the canting hook and button height (On Of) on the center stove $(6.8 \mathrm{Cm})$.

The hope is that after the research can be done a new combatric can be made so that the wishes of users can be fulfilled.

Keywords: House of Quality, Characteristics of electric batik stove, QFD

\section{PENDAHULUAN}

Batik sebagai salah satu kekayaan budaya Indonesia yang banyak diminati dan kemungkinan akan lebih berkembang melihat rencana dalam meningkatkan ekspor tenun dan batik ke luar negeri. Proses pembuatan batik adalah dengan menorehkan malam atau lilin panas pada kain mori menggunakan canting batik. Dalam memanaskan malam digunakan kompor.

Kompor yang digunakan oleh para pengrajin batik adalah kompor dengan bahan bakar minyak tanah. Menurut Dedi, dkk dalam [3] salah satu pengganti minyak tanah adalah listrik sebagai bahan bakar kompor batik elektrik. Kompor batik elektrik yang digunakan dalam proses membatik berbeda bentuknya dengan kompor elektrik umumnya dipasaran. Kompor batik elektrik menggunakan wajan permanen dibagian atas kompor dan juga heater dan thermostart sebagai pengatur suhu, serta antara wajan dan kompor dibuat statis (tidak bergerak), agar cairan malam tidak tumpah. [1]. Dalam pemakainanya kompor tersebut proses membatik membutuhkan 
kesabaran dan kehati-hatian saat meletakkan canting sehingga membutuhkan waktu yang lebih lama.

Berdasarkan penjelasan diatas kompor batik elektrik dipakai saat ini masih belum sesuai dengan kebutuhan para pengrajin batik, sehingga perlu dilakukan redesain kompor batik elektrik sesuai keinginan pengrajin dengan menggunakan metode QFD (Quality Function Deployment). QFD merupakan salah satu tool (metode) atau manajemen kualitas, yang diajukan untuk menggali keinginan, harapan konsumen berupa suara pelanggan atau Voice of Customer (VOC) akan suatu produk atau jasa sesuai yang diinginkan konsumen, dengan memperhatikan kemampuan pihak pengelola atau pihak industri [4].

\section{METODE PENELITIAN}

2.1 Objek Penelitian dan Subyek Penelitian

1. Penelitian ini dilakukan di Laboratorium Proses Produksi Jurusan Teknik Industri Universitas Widya Mataram Yogyakarta.

2. Penelitian ini difokuskan pada redesain kompor batik elektrik/kombatrik

\subsection{Alat Yang Digunakan}

Alat yang digunakan dalam penelitian ini adalah:

1. Kompor batik elektrik saat ini /kombatrik lama

2. Camera digital untuk mendokumentasikan proses penelitian.

3. Kuesioner kepuasan dan kepentingan berdasarkan karakteristik kebutuahan pengguna untuk mengukur tingkat kepuasan dan kepentingan pengguna.

\subsection{Langkah-langkah Penelitian}

1. Identivikasi variabel

a. Identifikasi Kuisioner, kuesioner penelitian ini dibagi menjadi dua bagian pertama berisi tentang data karakteristik responden yang memuat informasi nama, jenis kelamin, usia dan bagian ke dua terbagi menjadi dua bagian yang berisi tentang kepuasan responden terhadap kompor batik elektrik lama dan berisi tentang kepentingan responden terhadap kompor batik elektrik/kombatrik.

b. Identifikasi Sampel, sampel yang dipakai dalam penelitian ini adalah: Sebagian para pengrajin batik yang ada di UKM batik Yogyakarta sebayak 30 orang pengrajin atau responden yang umurnya 20 - 50 tahun dan pernah memakain.

2. Jenis kelamin yang sebagai subyek dipilih berjenis kelamin perempuan.

3. Pembuatan kuesioner berdasarkan karakteristik kebutuhan pengguna kompor batik elektrik yang akan dipakai dalam penentukan kepuasan dan kepentingan konsumen, untuk menentukan atribut kebutuhan pengguna kompor batik elektrik sesuai kebutuhan yang pokok dan sekunder yaitu: (1) Aman, (2) Model, (3) Kesesuaian ukuran, (4) Nyaman.

4. Pengisian kuesioner dilakukan oleh pengguna.

5. Pengumpulan data, meliputi data hasil kuesioner tentang kepuasan dan kepentingan pengguna yang akan dipakai untuk evaluasi dan analisis.

6. Pengolahan data

a. Pengolahan data yang dilakukan adalah sebagai berikut:

1. Pengolahan data kuesioner I dengan menghitung prosentase pada setiap butir pertanyaan yang dipakai dalam penentuan atribut sebagai dasar pembuatan kuesioner II.

2. Berdasarkan data dari kuesioner II yang diperoleh dilakukan pengolahan data tentang tingkat kepentingan dan tingkat kepuasan responden/pengguna sebagai dasar dalam redesain dengan menggunakan metode QFD.

3. Perancangan QFD, yang diawali dengan pembentukan diagram HOQ secara berurutan dengan menterjemahkan kebutuhan konsumen kedalam langkah-langkah operasional [6].

b. Langkah-langkah operasional yaitu:

1. Melakukan identifikasi semua kebutuhan dan keinginan konsumen terhadap produk atau jasa yang ada.

2. Mengidentifikasikan tingkat kepentingan konsumen untuk masing-masing karakteristik konsumen yang telah ada. 
3. Menerjemahkan seluruh kebutuhan dan keinginan konsumen (Whats) ke dalam karakteristik desain (Hows).

4. Menentukan hubungan yang terjadi antara masing-masing karakteristik konsumen dengan karakteristik desain.

5. Menentukan target perusahaan terhadap masing-masing karakteristik dari desain

6. Membentuk matrik korelasi yang menunjukkan hubungan antar masing-masing karakteristik desain yang ada.

7. Dengan menetapkan nilai-nilai yang berupa angka pada matriks hubungan keinginan konsumen dan karakteristik desain maka seluruh penilaian dapat disusun berdasarkan kepentingan relatif dari setiap kebutuhan dan keinginan konsumen.

7. Pembuatan desain kompor batik elektrik berdasarkan karakteristik-karakteristik yang dikembangkan.

\subsection{Diagram Alir Penelitian}

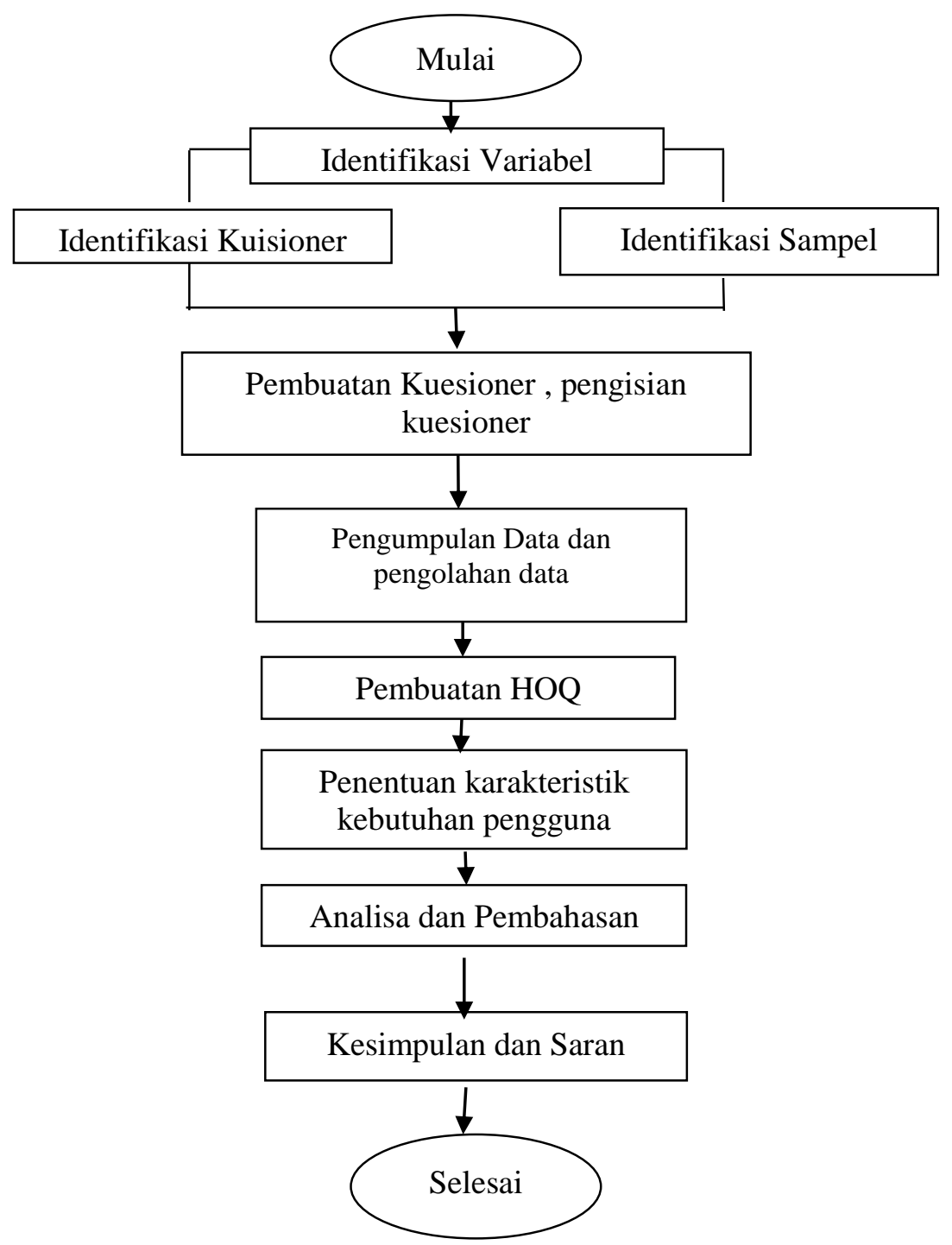

Gambar 3.1. Diagram Alir Penelitian 


\section{HASIL DAN PEMBAHASAN}

\subsection{Data Hasil Penelitian}

Data yang diperoleh berupa data hasil dari penyebaran kuesior I tanggapan pengguna terhadap kombatrik lama, dipakai dalam penentuan atribut pada pembuatan kuesioner II tentang kepentingan dan kepuasan pengguna Kombatrik lama. Adapun data tersebut sesuai dengan tabel 1 yaitu data hasil dari kuesioner I.

Tabel 1. Tanggapan Dari 30 Pengguna Terhadap Kombatrik Lama

\begin{tabular}{|c|c|c|c|c|}
\hline No & Atribut & Keterangan & Jumlah & $\begin{array}{c}\text { Prosentase } \\
(\%)\end{array}$ \\
\hline \multirow{3}{*}{1} & \multirow{3}{*}{$\begin{array}{l}\text { Penggunaan Kompor Batik } \\
\text { Elektrik saat ini }\end{array}$} & Mudah & 5 & 16,7 \\
\hline & & Sedang & 15 & 50,0 \\
\hline & & Susah & 10 & 33,3 \\
\hline \multirow{3}{*}{2} & \multirow{3}{*}{$\begin{array}{l}\text { Berapa lama anda membatik } \\
\text { dengan kompor batik elektrik }\end{array}$} & $>1$ tahun & 15 & 50,0 \\
\hline & & $>3$ tahun & 15 & 50,0 \\
\hline & & $>5$ tahun & 0 & 00,0 \\
\hline \multirow{3}{*}{3} & \multirow{3}{*}{$\begin{array}{l}\text { Saat persiapan untuk } \\
\text { menggunakan kompor batik } \\
\text { elektrik butuh waktu }\end{array}$} & Cepat & 11 & 36,7 \\
\hline & & Sedang & 13 & 43,3 \\
\hline & & Lambat & 6 & 20,0 \\
\hline \multirow{3}{*}{4} & \multirow{3}{*}{$\begin{array}{l}\text { Apakah ada kesulitan dalam } \\
\text { meletakan canting diwajan kompor } \\
\text { batik elektrik }\end{array}$} & Tidak & 21 & 70,0 \\
\hline & & Lumayan & 7 & 23,3 \\
\hline & & Sangat sulit & 2 & 06,7 \\
\hline \multirow{3}{*}{5} & \multirow{3}{*}{$\begin{array}{l}\text { Apakah bahan penampung malam } \\
\text { batik }\end{array}$} & Kuningan & 9 & 30,0 \\
\hline & & Almunium & 1 & 03,3 \\
\hline & & Tembaga & 20 & 66,7 \\
\hline \multirow{3}{*}{6} & \multirow{3}{*}{$\begin{array}{l}\text { Bagaimana meletakan canting } \\
\text { batik elektrik pada saat proses }\end{array}$} & Mudah & 15 & 50,0 \\
\hline & & Sedang & 9 & 20,0 \\
\hline & & Susah & 6 & 10,0 \\
\hline \multirow{3}{*}{7} & \multirow{3}{*}{$\begin{array}{l}\text { Apakah panas yang stabil sangat } \\
\text { anda butuhkan }\end{array}$} & Tidak & 0 & 00,0 \\
\hline & & Lumayan & 3 & 10,0 \\
\hline & & Sangat perlu & 27 & 90,0 \\
\hline \multirow{3}{*}{8} & \multirow{3}{*}{$\begin{array}{l}\text { Apakah Kompor Batik elektrik } \\
\text { sering rusak }\end{array}$} & Tidak & 3 & 10,0 \\
\hline & & Jarang & 7 & 23,3 \\
\hline & & Sering & 20 & 66,7 \\
\hline \multirow{3}{*}{9} & \multirow{3}{*}{$\begin{array}{l}\text { Pada Kompor Batik elektrik bagian } \\
\text { mana yang sering rusak }\end{array}$} & Kerangka & 19 & 63,3 \\
\hline & & Konduktor & 9 & 30,0 \\
\hline & & Tempat malam & 2 & 06,7 \\
\hline \multirow{3}{*}{10} & \multirow{3}{*}{ Apakah penyebab kerusakannya } & Kualitas alat & 9 & 30,0 \\
\hline & & Kesalahan sendiri & 3 & 10,0 \\
\hline & & Model & 18 & 60,0 \\
\hline \multirow{3}{*}{11} & \multirow{3}{*}{$\begin{array}{l}\text { Apakah Badan Pada kompor batik } \\
\text { elektrik sudah memadai }\end{array}$} & Belum & 17 & 56,7 \\
\hline & & Cukup & 9 & 30,0 \\
\hline & & Sudah & 4 & 13,3 \\
\hline \multirow{3}{*}{12} & \multirow{3}{*}{$\begin{array}{l}\text { Apakah bentuk kompor batik } \\
\text { elektrik sudah mencukupi } \\
\text { keinginan anda }\end{array}$} & Belum & 15 & 50,0 \\
\hline & & Cukup & 5 & 16,7 \\
\hline & & Sudah & 10 & 33,3 \\
\hline \multirow{3}{*}{13} & & Tidak & 3 & 10,0 \\
\hline & elektrik mempengaruhi proses & Sedang & 6 & 20,0 \\
\hline & & Sangat & 21 & 70,0 \\
\hline & & Tidak & 20 & 66,7 \\
\hline 14 & Apakah posisi tombol kompor & Cukup & 6 & 20,0 \\
\hline & batık elektrık dırasakan nyaman & Nyaman & 4 & 13,3 \\
\hline
\end{tabular}


Data hasil dari kuesioner I yang terdiri dari 14 pertanyaan dipakai dasar dalam penentuan karakteristik kebutuhan pengguna kompor batik elektrik yang terdiri dari 8 atribut adalah 1) Tidak mengerak (A); 2) Panas malam stabil (B); 3) Bahan penghantar panas (C); 4) Tidak mudah tumpah (D); 5) Tidak mudah rusak (E); 6) Bentuk Kompor (F); 7) Posisi tombol (G); 8) Lebih mudah digunakan $(\mathrm{H})$ untuk membuat kuesioner II yang hasiknya sesuai tabel 2.

Tabel 2. Hasil Tingkat Kepuasan dan Tingkat Kepentingan Pengguna

\begin{tabular}{|c|c|c|c|c|c|c|c|c|c|c|c|}
\hline \multirow{2}{*}{ No } & \multirow{2}{*}{ Atribut } & \multicolumn{5}{|c|}{ Tingkat Kepuasan } & \multicolumn{5}{|c|}{ Tingkat Kepentingan } \\
\hline & & (5) & (4) & (3) & (2) & (1) & (5) & (4) & (3) & (2) & (1) \\
\hline 1 & A & 6 & 22 & 2 & 0 & 0 & 0 & 17 & 13 & 0 & 0 \\
\hline 2 & B & 1 & 22 & 7 & 0 & 0 & 2 & 20 & 8 & 0 & 0 \\
\hline 3 & $\mathrm{C}$ & 0 & 12 & 18 & 0 & 0 & 4 & 16 & 10 & 0 & 0 \\
\hline 4 & $\mathrm{D}$ & 0 & 21 & 9 & 0 & 0 & 1 & 20 & 9 & 0 & 0 \\
\hline 5 & $\mathrm{E}$ & 2 & 18 & 10 & 0 & 0 & 4 & 14 & 12 & 0 & 0 \\
\hline 6 & $\mathrm{~F}$ & 0 & 0 & 7 & 23 & 0 & 16 & 13 & 1 & 0 & 0 \\
\hline 7 & $\mathrm{G}$ & 0 & 00 & 14 & 16 & 0 & 19 & 11 & 0 & 0 & 0 \\
\hline 8 & $\mathrm{H}$ & 1 & 21 & 8 & 0 & 0 & 0 & 16 & 14 & 0 & 0 \\
\hline
\end{tabular}

Keterangan :

5 = Sangat Penting $=$ Sangat Puas; $4=$ Penting $=$ Puas; $3=$ Cukup Penting $=$ Cukup Puas; $2=$ Tidak Penting $=$ Tidak Puas; $1=$ Sangat Tidak Penting $=$ Sangat Tidak Puas.

Berdasarkan tabel 3 diperoleh besarnya nilai rata-rata tingkat kepuasan dan tingkat kepentingan dari resmonden sesuai tabel 3.

Tabel 3. Rata-rata Tingkat Kepuasan dan Tingkat Kepentingan Responden

\begin{tabular}{|c|l|c|c|}
\hline No & \multicolumn{1}{|c|}{ Atribut } & $\begin{array}{c}\text { Tingkat } \\
\text { Kepuasan }\end{array}$ & $\begin{array}{c}\text { Tingkat } \\
\text { Kepentingan }\end{array}$ \\
\hline 1 & Tidak mengerak (A) & 4,13 & 3,7 \\
\hline 2 & Panas malam stabil (B) & 3,8 & 3,97 \\
\hline 3 & Bahan penghantar panas (C) & 3,4 & 3,93 \\
\hline 4 & Tidak mudah tumpah (D) & 3,7 & 3,9 \\
\hline 5 & Tidak mudah rusak (E) & 3,73 & 3,87 \\
\hline 6 & Bentuk Kompor (F) & 2,23 & 4,67 \\
\hline 7 & Posisi tombol (G) & 2,47 & 4,8 \\
\hline 8 & Lebih mudah digunakan (H) & 3,77 & 3,67 \\
\hline
\end{tabular}

\subsection{Pembahasan}

3.2.1 Penentuan Karakteristik kebutuhan pengguna untuk di QFDkan dari ke8 atribut berdasarkan hasil rata-rata Tingkat Kepuasan dan Tingkat Kepentingan dalam tabel 4, maka semua atribut yang dipakai dalam pembuatan HOQ, karena kedelapan atribut mempunyai nilai rata-rata tingkat kepentingannya diatas 3,5 .

\subsubsection{Metode Quality Function Deployement (QFD)}

Tahap Penyusunan Rumah Kualitas/Matrik Perencanaan Produk (House of Quality) dalam pembuatan matrik perencanaan produk yang perlu diperhatikan mengenai langkah-langkahnya. Langkah-langkah dalam pembuatan HOQ adalah:

1. Menentukan Tingkat Kepentingan dan Kepuasan berdasarkan tabel 3, untuk menentukan besarnya nilai Kepentingan absoluts sesuai dengan data hasil tingkat kepentingan dari pengguna dan besarnya nilai kepentingan relatif dapat diperoleh sesuai tabel 4 . 
Sebagai contoh untuk atribut tidak menggerak (A) adalah 3,7 dan besarnya nilai :

$$
\begin{aligned}
\text { Nilai kepentingan relativf } & =\frac{3,7}{32,51} * 100 \% \\
& =11,38
\end{aligned}
$$

Tabel 4. Nilai Kepentingan absolud dan Tingkat Kepentingan Relatif

\begin{tabular}{|c|l|c|c|}
\hline No & \multicolumn{1}{|c|}{ Atribut Kualitas Produk } & $\begin{array}{c}\text { Kepentingan } \\
\text { Absolut }\end{array}$ & $\begin{array}{c}\text { Kepentingan } \\
\text { Relatif }\end{array}$ \\
\hline 1 & Tidak mengerak (A) & 3,7 & 11,38 \\
\hline 2 & Panas malam stabil (B) & 3,97 & 12,21 \\
\hline 3 & Bahan penghantar panas (C) & 3,93 & 12,08 \\
\hline 4 & Tidak mudah tumpah (D) & 3,9 & 11,99 \\
\hline 5 & Tidak mudah rusak (E) & 3,87 & 11,9 \\
\hline 6 & Bentuk Kompor (F) & 4,67 & 14,36 \\
\hline 7 & Posisi tombol (G) & 4,8 & 14,76 \\
\hline 8 & Lebih mudah digunakan (H) & 3,67 & 11,28 \\
\hline \multicolumn{2}{r}{ Total } & 32,51 & \\
\hline
\end{tabular}

2. Menentukan Goal (Target).

Penentuan Goal ini berkaitan dengan kepuasan pengguna kompor batik elektrik lama terhadap tingkat perbaikan yang akan dilakukan oleh tim pengembang, untuk memenuhi tuntutan dari pengguna dan juga merupakan target performance dari masing-masing indikator kebutuhan pengguna sehingga memberikan Competitive Advantage atau keuntungan yang kompetitif tim pengembang serta pengguna yaitu: untuk nilai goal 4 atribut Tidak mengerak (A), Panas malam stabil (B), Bahan penghantar panas (C), Tidak mudah tumpah (D), Tidak mudah rusak (E) dan untuk niali goal 5 atribut Bentuk Kompor (F), Posisi tombol (G) dan Lebih mudah digunakan (H).

Nilai goal (target) terhadap indikator kualitas produk rata-rata mempunyai nilai 4 dan 5 artinya tim pengembang dalam meningkatkan kualitas Kompor batik elektrik lama mempunyai target yang positif, hal ini harus didukung dengan adanya perbaikan sehingga kebutuhan dan keinginan pengguna Kompor batik elektrik dapat terpenuhi.

\section{Rasio pengembangan (Improvement Ratio)}

Rasio ini memberikan bobot dari kebutuhan pelanggan yang akan membutuhkan pengembangan yang paling banyak. Rasio pengembangan merupakan perbandingan goal dan customer satisfication performance berdasarkan tabel 3 dan goal. Sebagai contoh perhitungan untuk atribut Tidak mengerak (A) maka Improvement Ratio $(A)=\frac{4}{4,13}=0,97$. Secara berurutan besarnya IR untuk: Atribut Tidak mengerak (A) IR = 0,97; Atribut Panas malam stabil (B) IR = 1,05; Atribut Bahan penghantar panas (C) IR = 1,18; Atribut Tidak mudah tumpah (D) IR = 1,08; Atribut Tidak mudah rusak (E) IR = 1,07; Atribut Bentuk Kompor (F) IR = 2,24; Atribut Posisi tombol (G) IR = 2,02 dan Atribut Lebih mudah digunakan (H) IR = 1,33.

\section{Menentukan Sales Point}

Sales point ditentukan oleh tim pengembang adapun nilai ini mencerminkan tingkat kepentingan yang dapat diperoleh bila dilakukan peningkatan perbaikan dan penyempurnaan indikator yang bersangkutan.

Nilai sales point yang paling umum digunakan adalah: [2] nilai 1: tanpa titik penjualan 1,2 : titik penjualan menengah; 1,5: titik penjualan ketat (kuat).

Untuk nilai sales point 1,2 adalah atribut kualitas produk Tidak mengerak (A), Panas malam stabil (B), Bahan penghantar panas (C), Tidak mudah rusak (E), Lebih mudah digunakan (H) dan nilai 1,5 adalah atribut Tidak mudah tumpah (D), Bentuk Kompor (F), Posisi tombol (G).

Nilai sales point mencerminkan tingkat kepentingan yang didapat dari tim pengembang terhadap perbaikan dan penyempurnaan indikator kebutuhan pengguna. 
5. Menentukan Bobot Kepentingan (Row Weight)

Raw Weight diperoleh dari rumus sebagai berikut [2]:

Raw Weigth $(A)=($ Importance to Customer $) x$ (Improvement Ratio) $x$ (Sales Point $)$

Sebagai contoh untuk atribut tidak menggerak (A):

Raw Weigth $(A)=(15,08) \times(0,97) \times(1,2)=17,55$.

Setelah dilakukan perhitungan dapat diketahui bahwa tingkat kepentingan pengguna terhadap setiap elemen berbeda-beda dengan Total Row weight sebesar 253,7. Elemen-elemen kebutuhan yang akan menjadi fokus peningkatan pada atribut berturut-turut dari yang terkecil:

1) Atribut Tidak menggerak dengan basarnya bobot kepentingan paling kecil sebesar 17,55.

2) Atribut Tidak mudah rusak dengan basarnya bobot kepentingan sebesar 20,25.

3) Atribut Panas stabil dengan basarnya bobot kepentingan sebesar 20,38.

4) Atribut Bahan penghantar panas dengan basarnya bobot kepentingan sebesar 23,8 .

5) Atribut Lebih mudah digunakan dengan basarnya bobot kepentingan sebesar 20,38.

6) Atribut Tidak mudah tumpah dengan basarnya bobot kepentingan sebesar 25,74

7) Atribut Posisi tombol dengan basarnya bobot kepentingan sebesar 59,27.

8) Atribut Bentuk kompor dengan basarnya bobot kepentingan paling besar sebesar 20,38.

6. Mencari Bobot Kepentingan normal Normalized Weight

Normalized Raw Weight didapat dari besarnya raw weight untuk setiap atributnya. Tahapan ini bertujuan untuk: Mengukur kebutuhan - kebutuhan pelanggan dan Menetapkan tujuan-tujuan performansi pelanggan

Sedangkan besarnya nilai Normalized Raw Weight sesuai dengan persamaan :

$$
\text { Normalized Raw Weight }=\frac{\text { Raw Weight }}{\text { Total Row Weight }}
$$

Sesuai dengan persamaan tersebut diperoleh besarnya nilai Raw Weight dan nilai Normalized Raw Weight sesuai dengan tabel 5.

Tabel 5. Hasil perhitungan Raw Weight dan Normalized Raw Weight

\begin{tabular}{|c|l|c|c|}
\hline No & \multicolumn{1}{|c|}{ Atribut Kualitas Produk } & Raw Weight & $\begin{array}{c}\text { Normalize Raw } \\
\text { Weight }\end{array}$ \\
\hline 1 & Tidak mengerak (A) & 17,55 & 0,06918 \\
\hline 2 & Panas malam stabil (B) & 20,38 & 0,08034 \\
\hline 3 & Bahan penghantar panas (C) & 22,67 & 0,08937 \\
\hline 4 & Tidak mudah tumpah (D) & 25,74 & 0,10147 \\
\hline 5 & Tidak mudah rusak (E) & 20,25 & 0,07983 \\
\hline 6 & Bentuk Kompor (F) & 63,94 & 0,25206 \\
\hline 7 & Posisi tombol (G) & 59,27 & 0,23369 \\
\hline 8 & Lebih mudah digunakan (H) & 23,86 & 0,09406 \\
\hline \multicolumn{2}{|r}{ Total } & 253,7 & \\
\hline
\end{tabular}

Dari Tabel 5 di atas diketahui bahwa atribut kualitas produk yang persentase normalize raw weight diatas $10 \%$ terdiri dari dua atribut adalah atribut "Bentuk kompor sebesar 25,2\% dan Posisi tombol sebesar 23,34\%". Hal ini disebabkan karena atribut tersebut merupakan atribut penting, berdasarkan karakteristik teknis yang dikehendaki pengguna dari sebuah produk yaitu tinggi tombol dan bentuk wajan.

7. Menentukan Respon Teknis (Technical Respons)

Respon teknis (technical respons) diperoleh dari brainstorming dengan pihak tim pengembang (balai dan peneliti) tentang proses yang telah dilakukan pada kualitas Kombartik untuk memenuhi kebutuhan dan keinginan pengguna. Berdasarkan VOC, respon teknis yang diberikan adalah sebagai berikut: 1) Konduktor; 2) Rangka; 3) Bentuk wajan; 4) Tinggi tombol; 5) Mekanisme.

8. Penentuan Matriks Korelasi Teknis

Pada tahap ini dianalisis hubungan antara kebutuhan pengguna dengan karakteristik teknik yang telah didefinisikan, sehingga diperoleh hubungan yang sangat kuat, kuat atau lemah. 
Penilaian ini menggunakan skala ordinal yaitu merupakan tingkat pengukuran data yang berupa urutan rangking data yang memberi arti data bahwa satu obyek lebih, sama, kurang, atau tidak sama jumlahnya dari atributnya dibandingkan dengan beberapa obyek lainnya. Nilai yang digunakan untuk menggambarkan keempat hubungan sebagai berikut: Untuk nilai 9 berarti hubungan kuat; Untuk nilai 3 berarti hubungan sedang; Untuk nilai 1 berarti hubungan lemah; Untuk nilai 0 berarti tidak ada hubungan [6].

Pemberian nilai hubungan didasarkan atas kualitatif yang diperoleh dari wawancara, melakukan observasi, pengalaman pengguna dan tim pengembang serta estimasi nilai dari peneliti. Hasil matrix hubungan kebutuhan konsumen terhadap karakteristik teknik sebagai berikut:

Untuk keinginan atribut A dengan karakteristik teknis rangka berhubungan sedang dan berhubungan kuat dengan bentuk wajan, untuk atribut B dengan karakteristik teknis konduktor dan bentuk wajan berhubungan kuat, untuk atribut $\mathrm{C}$ dengan karakteristik teknis mekanisme berhubungan sedang, untuk karakteristik D dengan karakteristik tekinis rangka dan mekanisme berhubungan sedang serta berhubungan kuat dengan bentuk wajan, untuk atribut E dengan karakteristik teknis konduktor dan mekanisme berhubungan sedang serta berhubungan lemah dengan rangka, Untuk atribut $\mathrm{F}$ dengan karakteristik teknis rangka, bentuk wajan dan tinggi tombol berhubungan sedang, untuk atribut $G$ dengan karakteristik teknis rangka berhulungan lemah dan tinggi tombol berhubungan kuat serta dengan mekanisme berhubungan sedang, sedangkan untuk atribut $\mathrm{H}$ dengan karakteristik teknis tinggi tombol berhubungan sedan dan dengan mekanisme berhubungan kuat.

\section{Mencari Nilai Kepentingan Teknis}

Nilai kepentingan teknis digunakan untuk mengetahui nilai kebutuhan atau kepentingan teknis masing-masing atribut sehingga dapat diketahui atribut mana yang mempunyai nilai kepentingan teknis tertinggi ataupun yang terendah. Terdapat dua macam nilai kepentingan teknis yaitu nilai kepentingan teknis absolut (Absolute Importance) dan nilai kepentingan relatif (Relative Importance).

Untuk menghitung nilai kebutuhan atau kepentingan teknis menggunakan rumus :

$$
K t_{i}=\sum_{i=1}^{n} \mathrm{Bt} * \mathrm{H}_{\mathrm{i}}
$$

Besarnya nilai tingkat kepentingan absolut dari masing masing atribut dapat dicari berdasarkan nilai kepentingan teknis masing-masing atribut sebagai contoh perhitungan :

Untuk nilai atribut Konduktor :

$$
\begin{aligned}
\mathrm{Kt}_{\text {Konduktor }} & =(20,38 * 9)+(20,25 * 3) \\
& =244,17
\end{aligned}
$$

Untuk perhitungan Kepentingan Relatif (Relative Importance), diperoleh dari hasil bagi masing-masing Kepentingan Absolut (Absolut Importance) dengan jumlah total kepentingan absolut dikalikan $100 \%$ dengan persamaan:

$$
\text { Kepentingan Relatif }=\frac{K t_{i}}{\sum K t} \times 100 \%
$$

Hasilnya data kepentingan absolut dan kepentingan relatif serta prioritas berdasarkan penyesuaian tingkat kepentingan perhitungannya sama tetapi nilai importace to costomer menggunakan nilai hasil dari penyesuaian. Hasil dapat dilihat dalam tabel 6 .

Tabel 6. Kepentingan Absolut dan Kepentingan Relatif

\begin{tabular}{|c|l|c|c|c|}
\hline No & Kebutuhan Teknis & $\begin{array}{c}\text { Tingkat } \\
\text { Kepentingan } \\
\text { Absolut }\end{array}$ & $\begin{array}{c}\text { Tingkat } \\
\text { Kepentingan } \\
\text { Relatif }(\%)\end{array}$ & Prioritas \\
\hline 1 & Konduktor & 244,17 & 8,703 & 5 \\
\hline 2 & Rangka & 401,21 & 14,3 & 4 \\
\hline 3 & Bentuk wajan & 764,85 & 27,262 & 2 \\
\hline 4 & Tinggi tombol & 796,83 & 28,402 & 1 \\
\hline 5 & Mekanisme & 598,53 & 21,333 & 3 \\
\hline
\end{tabular}


Dari 6 dapat diihat bahwa kontribusi karakteristik teknis kepada performansi produk atau jasa secara keseluruhan, secara berurutan berdasarkan besarnya nilai tingkat kepentingan yang terbesar sampai yang terkecil : 1) Tinggi tombol ; 2)Bentuk wajan; 3) Mekanisme; 4) Rangka dan 5) Konduktor.

\section{Penetuan target}

Mengingat hasil dalam menentukan target ini diperlukan informasi mengenai keinginan dan kebutuhan pengguna, kebutuhan teknis, serta evaluasi pembanding, maka dapat diperoleh ketentuan-ketentuan yang ingin dicapai dalam redesain Kombantrik adalah :

a. Tinggi tombol untuk memudahkan penggunaan maka Kombatrik baru posisi tombol On Of nya tidak dibagian bawah dan letaknya tidak berjajar dengan lampu kontrol, agar lebih tepat menjangkaunya dalam menghidup dan matikan kompor.

b. Bentuk wajan ditambah pengait canting supaya proses batik dapat berjalan dengan lancar, saat menaruh canting di wajan. Dibagian pinggir wajan dikasih lobang pengait untuk menempatkan canting yang tidak dipakai membatik agar tidak jatuh ke dalam wajan.

c. Mekanisme masih sama seperti Kombatrik lama tidak ada perubahan begitu juga konduktor serta rangka masih tetap sama seperti pada Kombatrik yang lama.

11. Hubungan Teknis

Hubungan teknis menunjukkan interaksi antara karakteristik teknis, yaitu pada masingmasing teknis dibandingkan satu sama lain. Korelasi teknik merupakan matrik yang menyerupai atap sehingga disebut roof matric. Simbol- sombol yang dipakai dalam menunjukkan hubungan antara karakteristik teknik yaitu: antara konduktor dengan rangka berhubungan lemah, bentuk wajan dan mekanisme berhubungan kuat, untuk rangka dengan tinggitombol berhubungan kuat dan untuk bentuk wajan dan mekanisme berhubungan lemah. Keseluruhan hasil pengolahan data diatas dimasukkan ke HOQ pada QFD. Penggunaan QFD didalam pembuatan rumah kualitas. Gambar rancangannya dapat dilihat pada gambar 1 .

\subsubsection{Analisis konsep}

Rincian kebutuhan kriteria dalam analisis konsep terdapat kriteria-kriteria yang merupakan rumusan rincian kebutuhan dari Kombatrik baru, yaitu :

1. Kebutuhan konsumen dari QFD, berdasarkan House of Quality maka ditentukan faktor teknik yang memungkinkan untuk diperbaiki adalah :

a. Tinggi tombol,

b. Bentuk wajan,

Mengingat hasil dari House of Quality berdasarkan metode QFD, sebagai dasar dalam melakukan redesain Kombatrik baru.

2. Kebutuhan karakteristik desain Kombatrik baru secara umum dibutuhkan pengguna adalah Kombatrik yang memiliki karakteristik: tinggi tombol mudah terjangkau, bentuk wajan yang multi fungsi sedangkan mekanisme atau pemakaiannya, konduktor serta rangka kompor masih tetap sama dengan Kombatrik lama.

\subsubsection{Penentuan spesifikasi akhir}

Penentuan akhir sangat sulit karena adanya trede off yaitu hubungan sdaling berlawanan antara dua spesifikasi yang sudah melekat pada konsep produk yang dipilih [5].

Desain Kombatrik yang dibuat nantinya akan lebih mudah penggunaanya, aman dalam penggunaannya, dan menarik digunakan (Semiotika produk). Desain Kombatrik baru dalam mekanisme, rangka dan konduktor masih sama, namun bentuk wajan dan tinggi tombol disesuaikan. Tinggi tombol diletakkan tersendiri supaya dalam pemakaiaanya bisa langsung ditekan on ofnya karena posisi sudah pas, sedangkan pada wajan ditambahkan kolongan pengait tempat meletakkan canting saat tidak dipakai.

Untuk lebih memudahkan dalam pembuatan desain Kombatrik baru meliputi:

1. Ukuran tinggi tombol lebih tinggi posisi ditengah dan tersendiri, Kombatrik yang lama tombol ada dibagian bawah dan sejajar dengan lampu kontrol. 
2. Dengan memberi kolongan pada pinggir wajan sebagai pengait agar canting tidak terlepas, Kombatrik yang lama wajan hanya diberi alur dibagian pinggirnya

\subsection{Pembuatan Desain Kombatrik}

Desain kombatrik yang baru ditunjukkan dalam gambar 2 untuk gambar 2 dimensi dan 2 b untuk gambar yang 3 dimensi
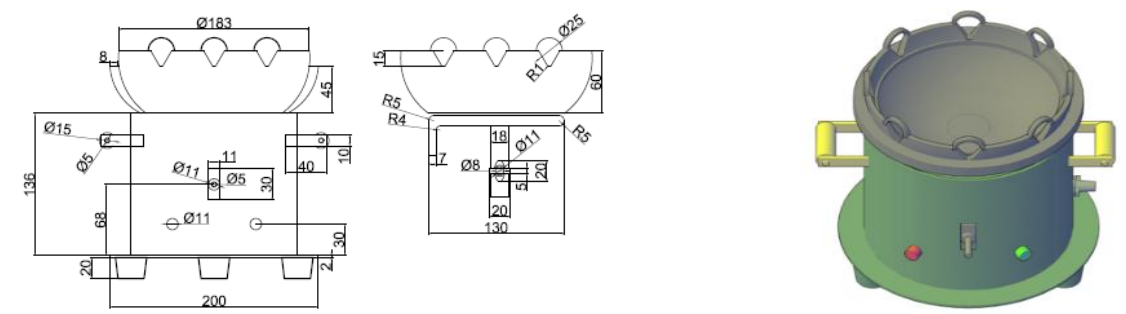

Gambar 2a. Desain kombatrik baru 2 D Gambar 2b. Desain kombatrik baru 3 D

\section{KESIMPULAN}

4.1 Kesimpulan

1. Karakteristik Kombatrik yang diperlukan pengrajin meliputi bentuk kompor dan posisi tombol (On Of).

2. Telah dibuat desain Kombatrik baru dengan bentuk wajan ditambah pengait canting dan tinggi tombol (On Of) pada kompor ditengah $(6,8 \mathrm{Cm})$

4.2 Saran

Agar pengrajin dapat terpenuhi keinginannya berdabut dibuatlah kompor batik elektrik Kombatrik yang baru

\section{UCAPAN TERIMA KASIH}

1. Ucapan Terima kasih kami sampaikan kepada LPPM UWM yang telah mendanai penelitian ini sehingga dapat diselesaikan dengan tepat waktu

2. Dekan FT dan Ka Prodi Teknik Industri UWM yang telah mendukung sehingga penelitian ini bisa berjalan dengan lancar

\section{DAFTAR PUSTAKA}

[1] Bya,G 2014 . Desain kompor Batik Elektrik menggunakan Metode Quality Function Deployment (QFD), Skripsi Tidak diterbitkan,

[2] Cohen, Lou. 1995. Quality Function Deployment : How To Make QFD WorkFor You. Massachuset : Addison-Wesley Publishing Company.

[3] http://elektronika-kelistrikan.blogspot.com/2018/07/pengertian-kompor-listrik.html 18 Januari 2019

[4] Kaebernick, H., L. E. Farmer, dan s. Mozar, 1997,Concurrent Product and Process Design, Sydney : UNSW.

[5] Ulrich, K.t. dan Eppinger, S.D., 2001, Perancangan dan Pengembangan Produk, Penerbit Salemba Teknika. Jakarta.

[6] Widodo, Imam Djati., 2003. Perencanaan dan Pengembangan Produk (Product Planning and Design). Yogyakarta : UII Press. 


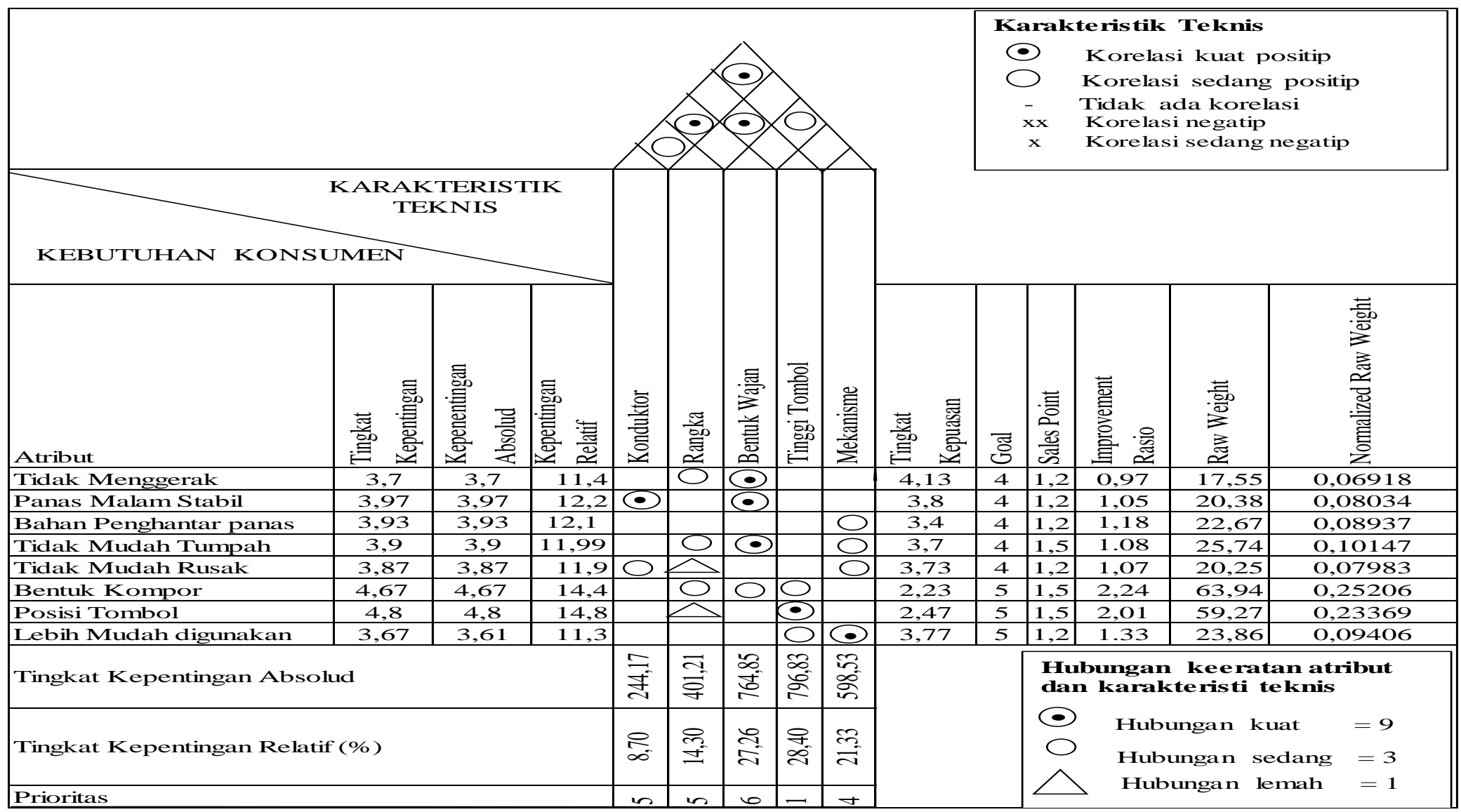

Gambar 1. Rumah Qualitas 
